\title{
Minimal dose of histamine for maximal acid secretion in control subjects and patients with duodenal ulcer*
}

\author{
H. G. DeSAI \\ M.D.(Bom.)
}

\author{
M. P. ZAVERI \\ B.Sc.(Bom.)
}

\author{
F. P. Antia \\ M.D.(Bom.), M.S.(Illi.), F.R.C.P.(Lond.) \\ Department of Gastroenterology, BYL Nair Charitable Hospital, \\ Dr A. L. Nair Road, Bombay 8
}

\begin{abstract}
Summary
Dose-response curves were obtained from forty adult male control subjects and forty patients with duodenal ulcer by administering $1 \cdot 6,2 \cdot 0,2 \cdot 4,2 \cdot 8,3 \cdot 2$ mg doses of histamine acid phosphate (HAP) subcutaneously.

The results showed that the minimal dose of HAP for MAO for patients with duodenal ulcer was significantly greater than that required for control subjects.

A significant positive correlation between the minimal dose of HAP, independent of body weight, for MAO and the maximal acid secretory capacity of an individual was observed both in control subjects and patients with duodenal ulcer.
\end{abstract}

THE smallest dose of histamine acid phosphate (HAP) for stimulating 'maximal' acid secretion was shown to be $0.04 \mathrm{mg} / \mathrm{kg}$ body weight on the subcutaneous histamine test (SHT) (Kay, 1953). Kay performed dose-response curves on SHT in five control subjects and five patients with duodenal ulcer only, and hence it was not determined whether subjects of these two groups with different parietal cell mass (PCM) (Cox, 1952) require the same or different doses for stimulating 'maximal' acid secretion.

The object of this study was to perform doseresponse curves on SHT in a large number of control subjects and patients with duodenal ulcer with a view to determining the minimal doses for maximal acid secretion in each group.

\section{Material and methods}

\section{Control subjects and patients}

SHT were performed in forty healthy adult male subjects (average age and weight 28.3 years and $47.6 \mathrm{~kg}$ respectively) and forty male patients (average age and weight 36.4 years and $47.0 \mathrm{~kg}$ respectively) with radiologically confirmed duodenal ulcer.

* Part of the work was supported by a grant from TNMC and BYL Nair Charitable Hospital Research Society.

\section{Method}

SHT were performed as described in a previous study (Desai, Zaveri \& Antia, 1970). Maximal acid output (MAO) (0-60 min) was calculated by the method of Card \& Marks(1960). Thirty-nine control subjects and thirty-six patients with duodenal ulcer received doses of $1 \cdot 6,2 \cdot 0,2 \cdot 4,2 \cdot 8,3 \cdot 2 \mathrm{mg}$ HAP subcutaneously and one control subject and four patients with duodenal ulcer, included from a previous study, (Desai, Borkar \& Jeejeebhoy, 1967), received 40, $50,60 \mu \mathrm{g} / \mathrm{kg}$ body weight doses of HAP. Six control subjects (with the minimal dose of HAP of $1.6 \mathrm{mg}$ for MAO) also received $1.2 \mathrm{mg}$ dose of HAP.

\section{Results}

Minimal dose of HAP (independent of, or in relation to body weight) for $M A O$

Control subjects. The mean and standard deviation (SD) of the minimal doses of HAP for MAO, independent of or in relation to body weight, were $2.4 \pm 0.51 \mathrm{mg}$ or $51.38 \pm 11.0 \mu \mathrm{g} / \mathrm{kg}$ body weight respectively on SHT.

Patients with duodenal ulcer. The mean and SD of the minimal doses of HAP for MAO, independent of, or in relation to body weight, were $2.68 \pm 0.36 \mathrm{mg}$ or $57.5 \pm 11.06 \mu \mathrm{g} / \mathrm{kg}$ body weight respectively on SHT.

The average minimal values of subcutaneous HAP for MAO in control subjects $(2.4 \mathrm{mg}$ or $51.38 \mu \mathrm{g} / \mathrm{kg}$ body weight) and patients with duodenal ulcer (2.68 $\mathrm{mg}$ or $57.5 \mu \mathrm{g} / \mathrm{kg}$ body weight) showed significant differences $(P<0.01$ and $P<0.05$ respectively).

\section{Maximal acid output and minimal dose of HAP for $M A O$}

Control subjects. A significant positive correlation was observed between MAO and the minimal dose of HAP independent of body weight, for MAO (Fig. $1 ; r=+0.45, P<0.01)$ but no correlation was observed with the minimal dose of HAP, in relation to body weight (Fig. 2; $r=+0.23, P>0.05$ ).

Patients with duodenal ulcer. A significant positive correlation was observed between MAO and the 


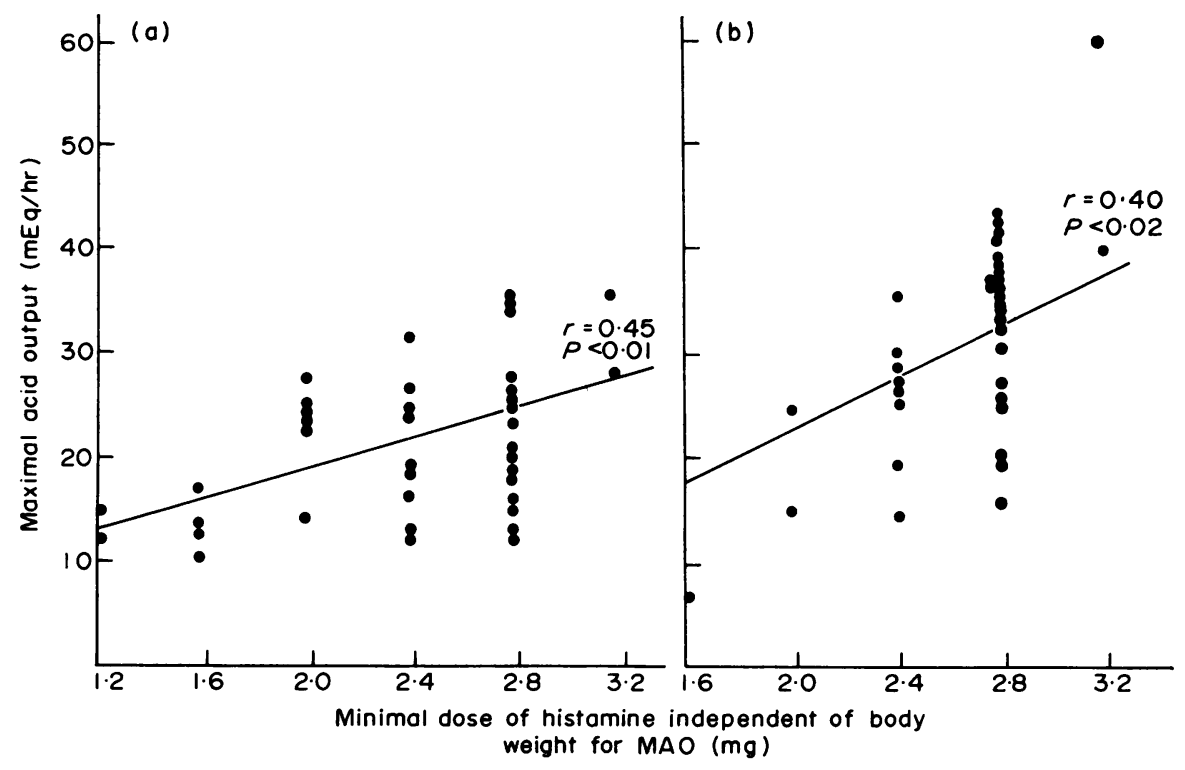

Fig. 1. Correlation between the maximal acid output and the minimal dose of HAP, independent of body weight, for MAO in (a) control subjects and (b) patients with duodenal ulcer.

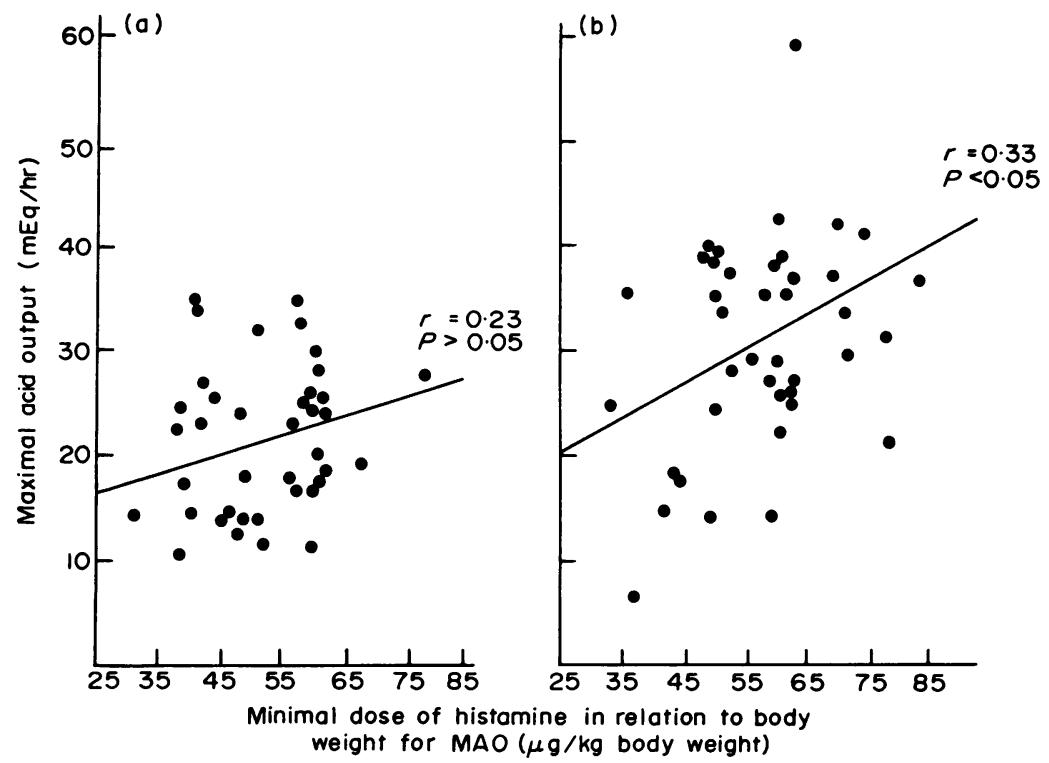

FIG. 2. Correlation between the maximal acid output and the minimal dose of HAP, in relation to body weight, for MAO in (a) control subjects and (b) patients with duodenal ulcer.

minimal dose of HAP, independent of body weight, for MAO (Fig. $1 ; r=+0.40, P<0.02$ ) and a positive correlation just significant at $5 \%$ level was also observed with the minimal dose of HAP, in relation to body weight (Fig. 2; $r=+0.33, P<0.05$ ).
Values of acid output with various doses of HAP

With different doses of HAP, values of acid output $\frac{\mathscr{D}}{\Phi}$ (Table 1) and the percentage response (when $100 \% \stackrel{\mathscr{Q}}{\rightarrow}$ represents the highest value observed in an individual) (Fig. 3) are shown both in control subjects 
and patients with duodenal ulcer. The values of acid output with a 1.6-mg dose of HAP were comparable in control subjects and patients with duodenal ulcer but values with a $2 \cdot 8-\mathrm{mg}$ dose of HAP were much higher in patients with duodenal ulcer compared with those in control subjects. The average percentage response with a $1 \cdot 6-\mathrm{mg}$ dose of HAP was appreciably lower in patients with duodenal ulcer compared with that in control subjects.

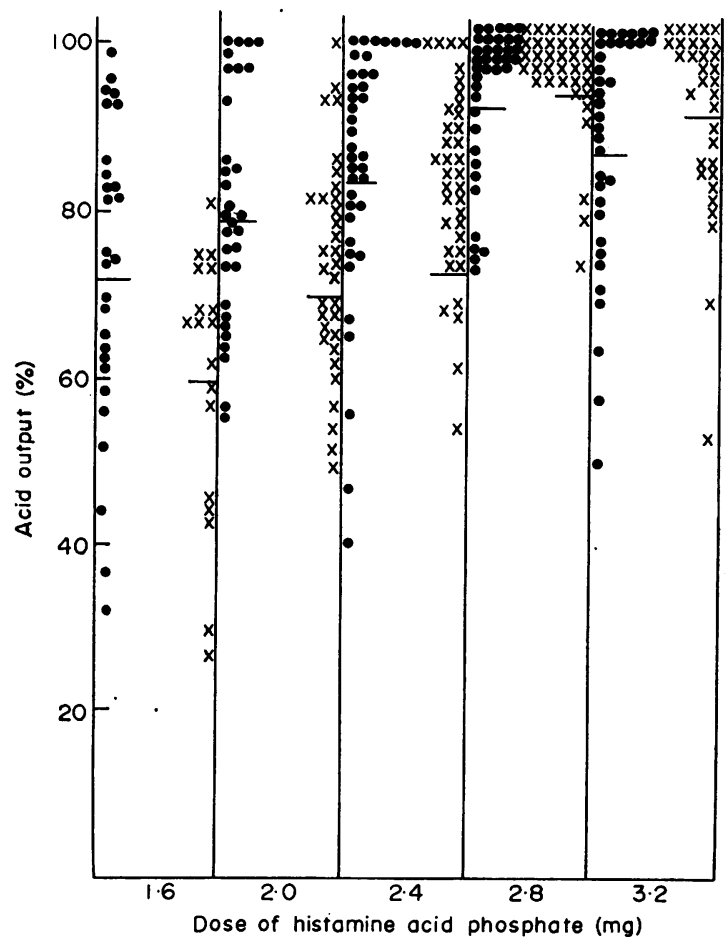

FIG. 3. Percentage response of maximal acid output with different doses of HAP in control subjects $(O)$ and patients with duodenal ulcer $(X)$ (when $100 \%$ represents the highest value observed in an individual).

\section{Discussion}

In the present study, the significant positive correlation observed between MAO and the minimal dose of HAP, independent of body weight, for MAO both in control subjects and patients with duodenal ulcer indicates that subjects with larger PCM will require a higher dose for stimulating maximal acid secretion. Since patients with duodenal ulcer on an average possess double the PCM present in control subjects (Cox, 1952), is is not surprising that a larger dose of HAP was required for patients with duodenal ulcer compared with that for control subjects. This observation is of some practical importance as the minimal dose of HAP for maximal acid secretion in control subjects will provide a submaximal stimulus to patients with duodenal ulcer secreting greater amount of acid.

With increasing doses of HAP, the values of acid output increasesharply in patients with duodenal ulcer but gradually in control subjects. The observation that values of acid output with a $1 \cdot 6-\mathrm{mg}$ dose of HAP were comparable in both groups but those with a 2.8-ing dose of HAP were much higher in patients with duodenal ulcer indicated that increased susceptibility of parietal cells to a stimulus is not responsible for higher values of acid output in patients with duodenal ulcer. In fact, the percentage response with a 1.6-mg dose of HAP was smaller in patients with duodenal ulcer than that in control subjects.

\section{Distribution of parietal cell mass}

Since the values of MAO on SHT showed a significant positive correlation with the PCM (Card \& Marks, 1960), it is possible to predict PCM values from MAO. In control subjects, the distribution of the PCM resembles the bell-shaped curve one observes in biological phenomena while it is not so for patients with duodenal ulcer (Fig. 4).

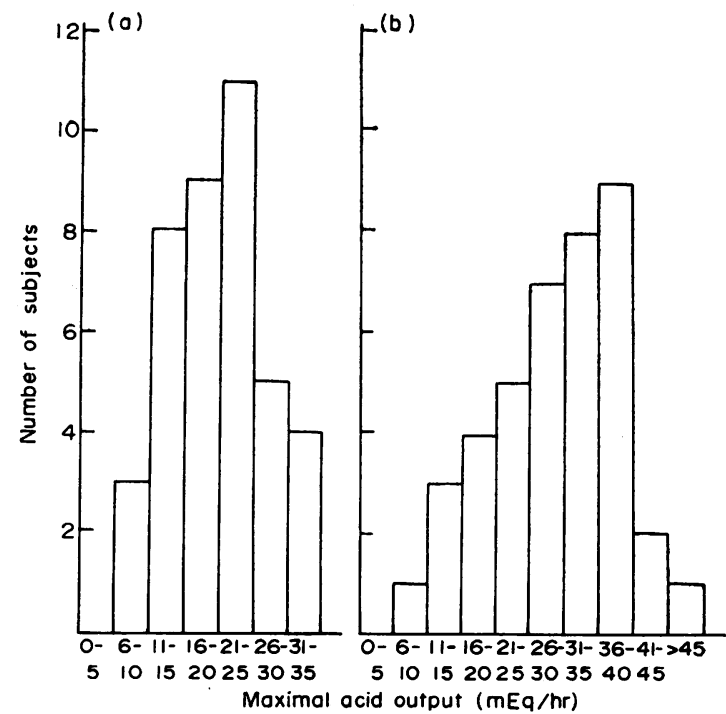

Fig. 4. Distribution of different values of maximal acid output observed in (a) control subjects and (b) patients with duodenal ulcer.

\section{Acknowledgments}

We are grateful to late Shri S. D. Ghanekar for his most valuable help in statistical evaluation of data. 
TABLE 1. Average values of acid output with different doses of histamine in control subjects and patients with duodenal ulcer

\begin{tabular}{|c|c|c|c|c|c|}
\hline \multirow{2}{*}{ Subjects } & \multicolumn{5}{|c|}{$\begin{array}{l}\text { Subcutaneous histamine acid phosphate } \\
\text { (mg) }\end{array}$} \\
\hline & $1 \cdot 6$ & $2 \cdot 0$ & $2 \cdot 4$ & $2 \cdot 8$ & $3 \cdot 2$ \\
\hline $\begin{array}{l}\text { Control subject } \\
(\mathrm{mEq} / \mathrm{hr})^{*}\end{array}$ & $\frac{13 \cdot 6 \pm \underset{(27)}{ \pm}}{6 \cdot 68}$ & $15 \cdot 4 \underset{(33)}{ \pm} 6 \cdot 11$ & $\begin{array}{c}17 \cdot 2 \pm 6 \cdot 57 \\
(39)\end{array}$ & $\frac{18 \cdot 6 \pm 6 \cdot 22}{(38)}$ & $8 \cdot \underset{(35)}{ \pm} 7 \cdot 89$ \\
\hline $\begin{array}{l}\text { Duodenal ulcer } \\
(\mathrm{mEq} / \mathrm{hr})^{*}\end{array}$ & $\begin{array}{c}14 \cdot 7 \pm 6 \cdot 63 \\
(18)\end{array}$ & $21 \cdot 3 \underset{(32)}{ \pm} 8 \cdot 06$ & $\begin{array}{c}24 \cdot 8 \pm 8.66 \\
(36)\end{array}$ & $\begin{array}{c}28 \cdot 8 \pm 10 \cdot 1 \\
(36)\end{array}$ & $27 \cdot 8 \underset{(32)}{ \pm} 10 \cdot 5$ \\
\hline
\end{tabular}

The figures in brackets refer to the number of subjects.

* Mean and SD of values of acid output with each dose of HAP.

\section{References}

CARD, W.I. \& MARKS, I.N. (1960) The relationship between the acid output of the stomach following 'maximal' stimulation and the parietal cell mass. Clinical Science, 19, 147.

Cox, A.J. (1952) Stomach size and its relation to chronic peptic ulcer. Archives of Pathology, 54, 407.
Desai, H.G., Borkar, A.V. \& Jeejeebhoy, K.N. (1967) Dose-weight relationship of histamine for maximal stimulation of gastric acid secretion. Gastroenterology, 53, 712.

Desai, H.G., ZAVERI, M.P. \& ANTIA, F.P. (1970) Comparison of dose-response curves with subcutaneous and intravenous histamine. Gastroenterology, 59, 701.

KAY, A.W. (1953) Effect of large doses of histamine on gastric secretion of $\mathrm{HCl}$-an augmented histamine test. British Medical Journal, 2, 77. 